\title{
DETECTION DAMAGE IN BEARING SYSTEM OF JET ENGINE USING THE VIBROACOUSTIC METHOD
}

\author{
Mariusz ŻOKOWSKI ${ }^{*}$, Paweł MAJEWSKI ${ }^{*}$, Jarosław SPYCHAŁA* \\ *Division for Aeroengines, Air Force Institute of Technology, ks. Bolesława 6, 01-494 Warsaw, Poland \\ zokowm@itwl.pl, majewp@itwl.pl, spychj@itwl.pl
}

received 10 October 2016, revised 25 September 2017, accepted 26 September 2017

\begin{abstract}
The article discusses typical, operational systems for monitoring vibrations of jet engines, which constitute the propulsion of combat aircraft of the Armed Forces of the Republic of Poland. After that, the paper presents the stage of installing vibration measuring sensors in the direct area of one of the jet engine bearings, which is a support system for its rotor. The article discusses results of carried out analyses of data gathered during tests of the engine in the conditions a jet engine test bed. Results of detecting damages to the bearing, using sensors built in the direct area will be presented.
\end{abstract}

Key words: Jet Engine, Damage Of Bearings, Vibroacoustic Method, Envelope Method

\section{INTRODUCTION}

Using vibroacoustic processes for diagnosing mechanical devices systems from many known reasons, with the basic one being the fact that, as a residual process, which accompanies the functioning of the machines, they are a good carrier of information about their technical condition. They reflect the most significant phenomena undergoing in the machines (e.g. impacts, deformations, stresses), on which their proper functioning depends (Bloke, Mitchel, 1972). Moreover, they are characterized by ease of measurement, high speed of transmitting information and a complex time, amplitude and frequency structure, which ensures their high utility in the form of possibility to assess the condition of the whole machine, as well as its elements. Whereas, for devices of simple construction, it is quite simple to distinguish between symptoms associated with proper (correct) functioning and the growing damage symptoms. In the case of more complex devices, with a jet engine being such, the issue is no longer so unambiguous (Cempel, 1989; Randall, 2011). Complex structure and disruption, e.g. from combustion processes, required adaptation of known measures of vibroacoustic signals or even the development of new ones. Because some of the jet engines operated by the Polish Armed Forces has only simple systems for monitoring their vibrations, which control the change of rotor imbalance and some do not have it at all, an important issue is the one of having reliable algorithms, possible to apply with the aim of an expanded and reliable evaluation of their technical condition, using additional control-measurement instruments. The article discusses effects of such works, associated with the installation of additional sensors in the direct area of the tested jet engine bearing and the detection of its damage (Report of the Division for Aeroengines of Air Force Institute of Technology, 2011).

\section{TYPICAL OPERATIONAL JET ENGINE VIBRATIONS MONITORING SYSTEMS}

Typical diagnostic systems used in the operation of combat aircraft jet engines, use the measurement of the body vibration at one point. For example, the A $\mathrm{L}-21 \mathrm{~F} 3$ engine, propulsion of the Su22 aircraft, has one sensor of the MB-27-1Г type, fixed on the front body of the compressor (Engine 88. Technical description and operating manual,1995). It is intended to process the linear speed of vibrations acting in horizontal radial direction on the electrical signals proportional to the movement speed of the magnet in the coil. It cooperates with a block of discreet commands BDK-89, which generates information for the vibration level indicator in the cabin's pilot. Signalling of an increased vibration level is activated, in the case of reaching, in the band $50 \div 200$ [Hz], a vibration speed equal to $88[\mathrm{~mm} / \mathrm{s}]$ in the engine rotational speed range of $54 \% \div 80 \%$ and after reaching a vibration speed equal to $55[\mathrm{~mm} / \mathrm{s}]$ in the engine rotational speed range over $80 \%$. Information about exceeding is also forwarded to the on-board recorded, as a single command. Moreover, information about the current vibration level is forwarded, via the engine monitoring connection, to the control panel of its parameters, during the on-ground test PNK-89 and is used to evaluate the vibration level at individual, stable ranges of the rotational speed.

A similar approach was used in the case of the RD-33 engine, which was the propulsion of the MiG-29. The vibration control system uses a sensor of the same type, the MB-27-1Г (Engine 89. Technical description,1998), installed on the body of the front supports of the high pressure compressor. It cooperates with a block of discreet commands BDK-88, which generates information for the vibration level indicator in the cabin's pilot, through illuminating a red signalling plate "Decrease rotations of the left (right)", displaying a signal "Vibrations of the left (right)" on the monitor of the "Screen", and a voice information "Vibrations of the left (right), decrease rotations of the left (right) engine". Signalling of an increased vibration level is activated, in the case of reaching 
a vibration speed higher than $30[\mathrm{~mm} / \mathrm{s}]$, in the band of rotational frequency changes, for a period of time longer than $3[\mathrm{~s}]$. Information about the current vibration speed value and exceeding the value, as a single command, is also given to the on-board recorder. Moreover, information about the current vibration level is forwarded, via the engine monitoring connection, to the control panel of its parameters, during the on-ground test PNK-88 and is used to evaluate the vibration level at individual, stable ranges of the rotational speed.

In the case of a jet engine form the TW3-117 family, which is the propulsion of the Mi-17 and Mi-24 helicopters, also one MB-03 sensor was used, fixed to the front body of the compressor (Helicopter Mi-24D. Technical description. Avionics, 1981). It is a supplementing element of the vibration control system IW-500Je (Fig. 4). At a vibration speed level equal to 45 [mm/s], it illuminates a yellow signalling plate in the pilot's cabin, saying "Left (right) engine increased vibrations". After reaching a vibration level of $60[\mathrm{~mm} / \mathrm{s}]$, red signal plate will illuminate, which says "Turn off left (right) engine". It also generates the above binary signals for the on-board recorder. A controlled range of frequencies covers the interval $190 \div 340[\mathrm{~Hz}]$, with the cut-off frequencies: lower - $90[\mathrm{~Hz}]$, upper $-680[\mathrm{~Hz}]$, and the irregularity of the amplitude characteristic $\leq 15 \%$. Sensitivity threshold $\leq 5[\mathrm{~mm} / \mathrm{s}]$.

A more complex engine vibration monitoring system was used in the Tu-154M aircraft with engines of the type D-30KU-154. It has two vibration measurement systems (Russian IW-50 (Engine D-30KU-154. Technical description and operating manual, 1992) and an additional AVM-219 made by Vibrolot). For each of the engines, the IW-50 system has two sensors: first one, installed in the area of the front support vertical peripheral direction, the second one in the area of the rear support vertical radial direction. The AVM-219 also has two sensors: the first one, installed in the front support area horizontal radial direction, however, shifted by

180 degrees in relation to the IW-50 sensor; the second one, in the rear support area horizontal radial direction. The recorder, for each of the engines, saves data on the values of vibrations, measured with three of the four available sensors (with the exception of vibrations measured with the sensor of the IW-50 system, installed in the front support area) and one binary signal, which informs about increased engine vibrations. The pilot's cabin has two control panels installed (one for each of the two, above mentioned systems), which allow to monitor the vibrations measured by each of the four sensors and a light signalling system, which informs about exceeding the vibrations for each of the engines separately. A vibration level of $55[\mathrm{~mm} / \mathrm{s}]$ causes the yellow signalling plate "Вибрация велика" to illuminate, while a level of 65 [mm/s], the red signalling plate "Опасная вибрация". Additionally, the AVM-219 system's control panel has a switch, which allows to control the value „2 $2 \times n_{2}-$ second harmonic of the rotational speed WWC", whose value is not recorded by the on-board recorder of the aircraft, but is only controlled during an on-ground test.

The discussed above, sample operational vibration measurement systems, as mentioned before, only deliver quantitative information and not qualitative, i.e., they inform about the change of an average vibration speed value in a band, covering a scope of changes of the engine's rotational frequency, rarely, its second multiplexing, without giving a reason of the changes. They are closed systems, with a limited measuring range, without the possibility of the user interfering in order to obtain additional diagnostic information. They also have a small number of sensors. That is why this study is an example of the possibility to diagnose, using sensors in new locations and applying new methodologies.

\section{GENERAL CHARACTERISTICS OF THE OBJECT AND CARRIED OUT WORKS}

The object of the test is the bearing (Żokowski at al., 2009), constituting a structural element of the middle support of the engine rotor, which is the main load of the bearing, as well as of the other two (Fig. 1.). The rotor is a seven-speed axial compressor and a single-speed, horizontal arm reaction turbine, couple with a splined coupling. The compressor with bearings is on the front trunnion in a ball bearing, with a separated inner ring (front bearing) and on the rear trunnion (middle bearing) in the roller bearing. The front shaft end is supported in the middle bearing of the power transmission, through a splined coupling and in the back end, in the roller bearing (rear bearing).

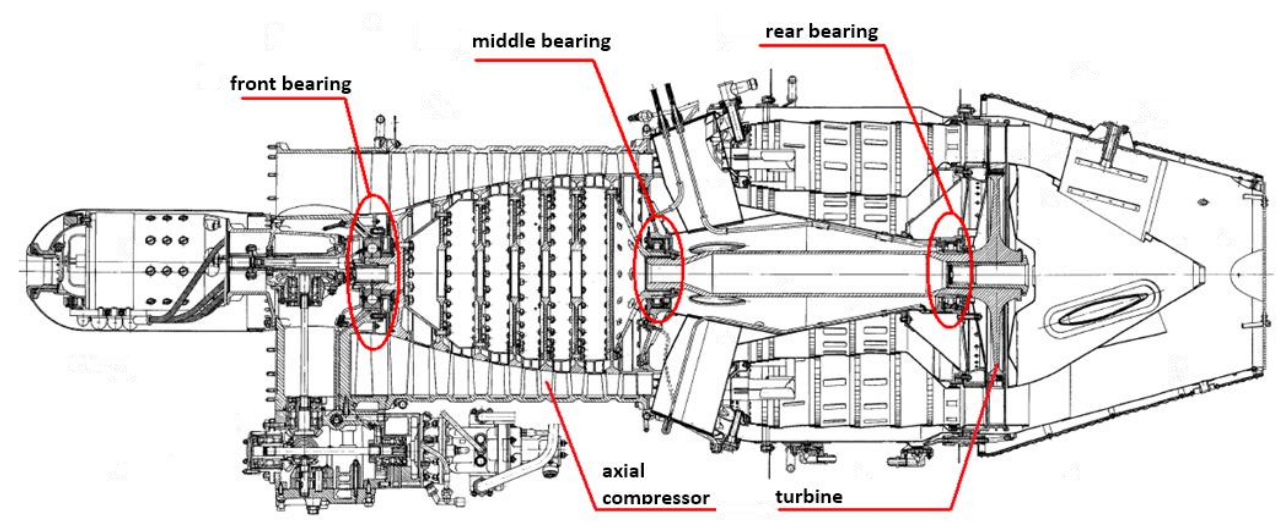

Fig. 1. Cross-section of the engine with marked bearings

As a result of structural, maintenance and operational factors, the operation would lead to damages of the middle bearing, detected by the personnel during maintenance service works. Moreover, the engine did not have a vibration measurement system.
That is why, the below studies confirm the possibility to detect damages of the bearing, through analysing the vibroacoustic signal (Dwojak, Rzepiela, 2003). That is why, inside the engine, on appropriate support, directly on the tested bearing, two single- 
axis piezoelectric vibration transmitters of the type 2248M1, made by Endevco (Fig. 2) were built, with one on the horizontal axis (point A marked PKY) and the second on the vertical axis (point $B$ marked PZY).
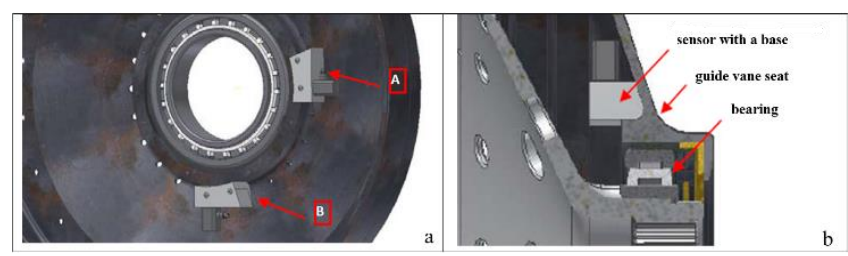

Fig. 2. Cross-section of the engine with marked bearings

Then, during the test of the engine in the engine test bed, with an operational bearing, followed by an implemented damage, the saved vibroacoustic signals were registered and analysed at a frequency of 25 [kHz]. The tested bearing was a used bearing, which came from an engine with the expired service life resource and the damage implemented (Żokowski et al., 2015), was in the form of the damage to one rolling element (Fig. 3a) and the inner race (Fig. 3b).

The envelope signal narrowband analysis method was used to analyse the signal (Report of the Division for Aeroengines of Air Force Institute of Technology, 2011; Muthukumarasamy and Ganeriwala, 2009). The results were juxtaposed in the form of a power spectrum of the determined envelopes: $f_{B P F O}-$ defect of the outer race, $f_{B P F I}$ - defect of the inner race, $f_{B S F}$ - defect of the rolling element, $f_{F T F}$ - defect of the rolling cage, for bearing parameters according to Tab. 1) and average power values of the an envelope, respectively, in the $Y$ and $Z$ axes, marked and Penv_PKY and Penv_PKZ.

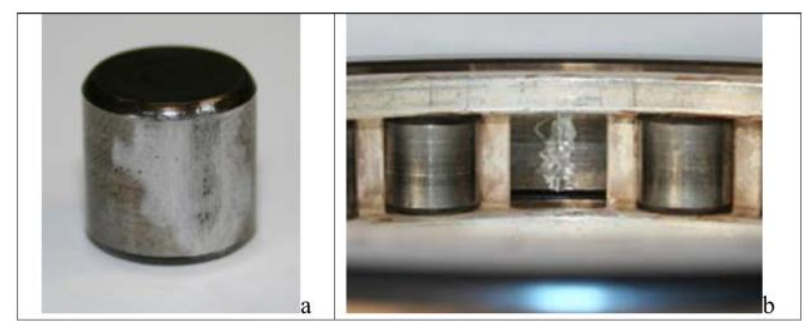

Fig. 3. Bearing damage form: $a$ - rolling element, $b$ - internal race

Tab. 1. View and parameters of the tested bearing

\begin{tabular}{|l|l|l|}
\hline Parameter name & Value \\
\hline $\begin{array}{l}\text { Number of rolling } \\
\text { elements }\end{array}$ & 22 \\
\hline $\begin{array}{l}\text { Rolling element } \\
\text { diameter }\end{array}$ & 10 \\
\hline Pitch diameter & 105 \\
\hline Contact angle & 0 \\
\hline
\end{tabular}

\section{TEST RESULTS}

Measurements of the signals generated by an operational bearing were taken during a cold start-up of the engine (without feeding and igniting fuel). Then, at rotor frequency of 32.7 [ Hz], the determined values of the bearing characteristic frequencies and their average power (Report of the Division for Aeroengines of Air Force Institute of Technology, 2011) were listed in Tab. 2 (with the center frequency of $6400[\mathrm{~Hz}]$ and band of $600[\mathrm{~Hz}]$. The envelope power spectrum for axes $Y$ and $Z$ is presented in Fig. 4 and 5 (Report of the Division for Aeroengines of Air Force Institute of Technology, 2011).

Tab. 2. Bearing parameters at rotor speed of $32.7[\mathrm{~Hz}]$

\begin{tabular}{|c|c|c|c|}
\hline Frequency designation & $f[\mathrm{~Hz}]$ & $\begin{array}{c}P_{\text {env_PKY }} \\
{\left[\left(\mathrm{m} / \mathrm{s}^{2}\right)^{2}\right]}\end{array}$ & $\begin{array}{c}P_{\text {env }} \text { PKZ } \\
{\left[\left(\mathrm{m} / \mathrm{s}^{2}\right)^{2}\right]}\end{array}$ \\
\hline $\mathrm{f}_{\mathrm{BPFO}}$ & 325.65 & 0.0242 & 0.0377 \\
\hline $\mathrm{f}_{\mathrm{BPFI}}$ & 394.21 & 0.0186 & 0.0352 \\
\hline $\mathrm{f}_{\mathrm{FTF}}$ & 14.8 & 0.0343 & 0.0486 \\
\hline $\mathrm{f}_{\mathrm{BSF}}$ & 170.23 & 0.0162 & 0.029 \\
\hline $0.5^{\star} \mathrm{f}_{\mathrm{BSF}}$ & 8511 & 0.0242 & 0.03 \\
\hline
\end{tabular}

Measurements of the signals generated by a damaged bearing were taken during a cold start-up of the engine (without feeding and igniting fuel) and during a hot test. For the cold start-up, at rotor frequency of $33.1[\mathrm{~Hz}$, the determined values of the bearing characteristic frequencies and their average power (Report of the Division for Aeroengines of Air Force Institute of Technology, 2011) were listed in Tab. 3 (with the center frequency of $6400[\mathrm{~Hz}]$ and band of $600[\mathrm{~Hz}]$. The envelope power spectrum for axes $Y$ and $Z$ is presented in Fig. 6 and 7 (Report of the Division for Aeroengines of Air Force Institute of Technology, 2011). For the hot test, at rotor frequency of 120.1 [Hz], the determined values of the bearing characteristic frequencies and their average power (Report of the Division for Aeroengines of Air Force Institute of Technology, 2011) were listed in Tab. 4 (with the center frequency of 6400 [Hz] and band of 1550 [Hz]. The envelope power spectrum for axes $Y$ and $Z$ is presented in Fig. 7 and Fig. 8 (Report of the Division for Aeroengines of Air Force Institute of Technology, 2011).

Tab. 3. Bearing parameters at rotor speed of $32.7[\mathrm{~Hz}]$

\begin{tabular}{|c|c|c|c|}
\hline Frequency designation & $f[\mathrm{~Hz}]$ & $\begin{array}{c}P_{\text {env_PKY }} \\
{\left[\left(\mathrm{m} / \mathrm{s}^{2}\right)^{2}\right]}\end{array}$ & $\begin{array}{c}P_{\text {env_PKZ }} \\
{\left[\left(\mathrm{m} / \mathrm{s}^{2}\right)^{2}\right]}\end{array}$ \\
\hline$f_{B P F O}$ & 329.91 & 0.0673 & 0.0751 \\
\hline$f_{B P F I}$ & 399.36 & 0.0306 & 0.0357 \\
\hline$f_{F T F}$ & 15.0 & 0.143 & 0.201 \\
\hline$f_{B S F}$ & 17245 & 0.0335 & 0.051 \\
\hline $0.5^{\star} f_{B S F}$ & 8623 & 0.0421 & 0.188 \\
\hline
\end{tabular}

Tab. 4. Bearing parameters at rotor speed of $120.1[\mathrm{~Hz}]$

\begin{tabular}{|c|c|c|c|}
\hline Frequency designation & $\mathrm{f}[\mathrm{Hz}]$ & $\begin{array}{c}P_{\text {env_PKY }} \\
{\left[\left(\mathrm{m} / \mathrm{s}^{2}\right)^{2}\right]}\end{array}$ & $\begin{array}{c}P_{\text {env_PKZ }} \\
{\left[\left(\mathrm{m} / \mathrm{s}^{2}\right)^{2}\right]}\end{array}$ \\
\hline $\mathrm{f}_{\mathrm{BPFO}}$ & 1194.64 & 3.3 & 1.4 \\
\hline $\mathrm{f}_{\mathrm{BPFI}}$ & 1447.35 & 0.5 & 1.2 \\
\hline $\mathrm{f}_{\mathrm{FTF}}$ & 54.35 & 2.5 & 4.5 \\
\hline $\mathrm{f}_{\mathrm{BSF}}$ & 624.9 & 1.5 & 3.9 \\
\hline $0.5^{\star} \mathrm{f}_{\mathrm{BSF}}$ & 312.5 & 2.7 & 4.8 \\
\hline
\end{tabular}



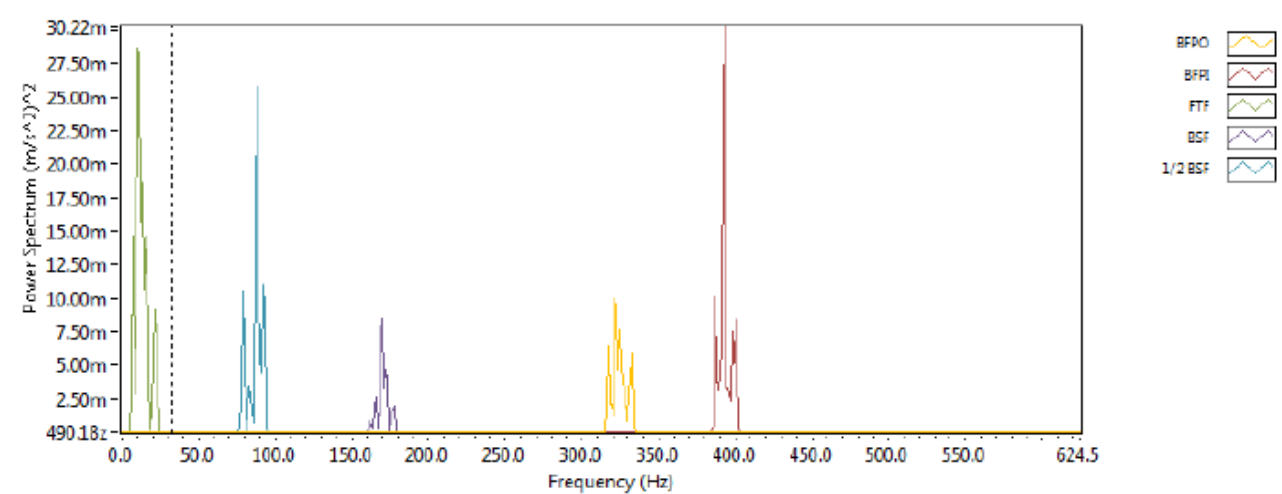

Fig. 4. Power spectrum determined with the envelope narrowband analysis method - point A
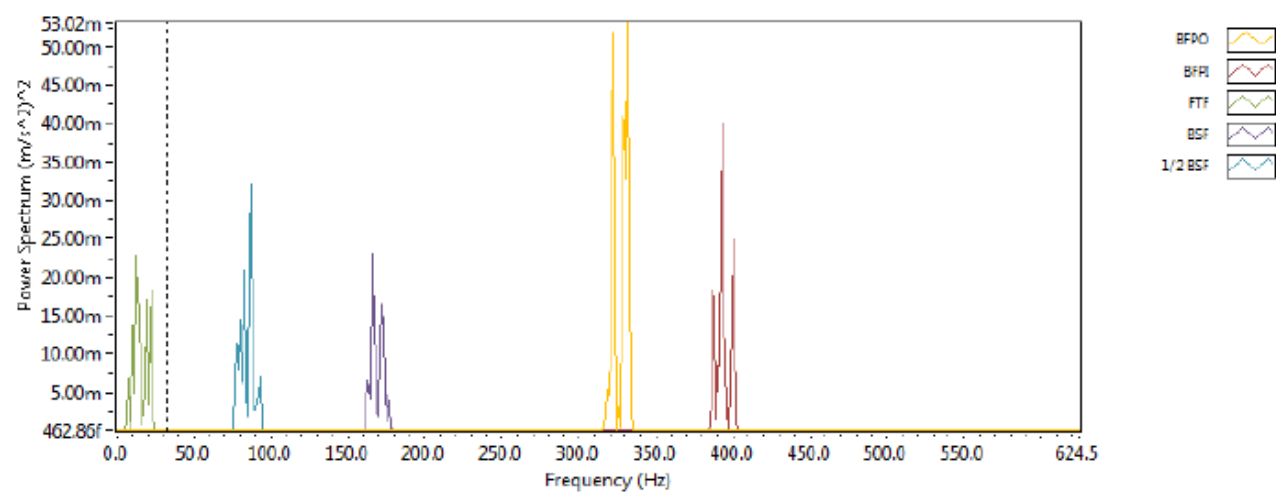

Fig. 5. Power spectrum determined with the envelope narrowband analysis method - point $B$
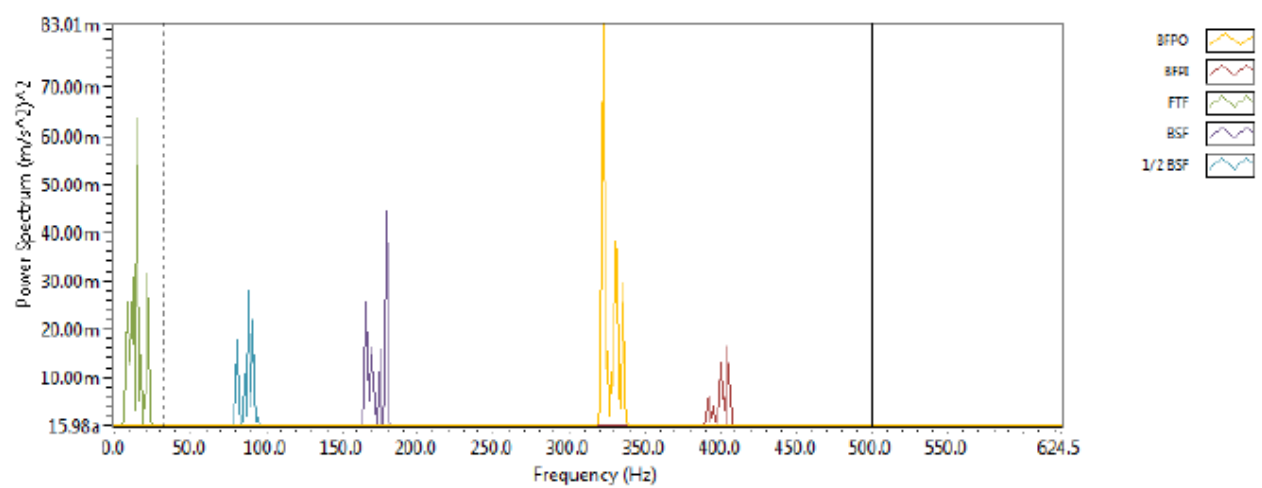

Fig. 6. Power spectrum determined with the envelope narrowband analysis method - point $A$
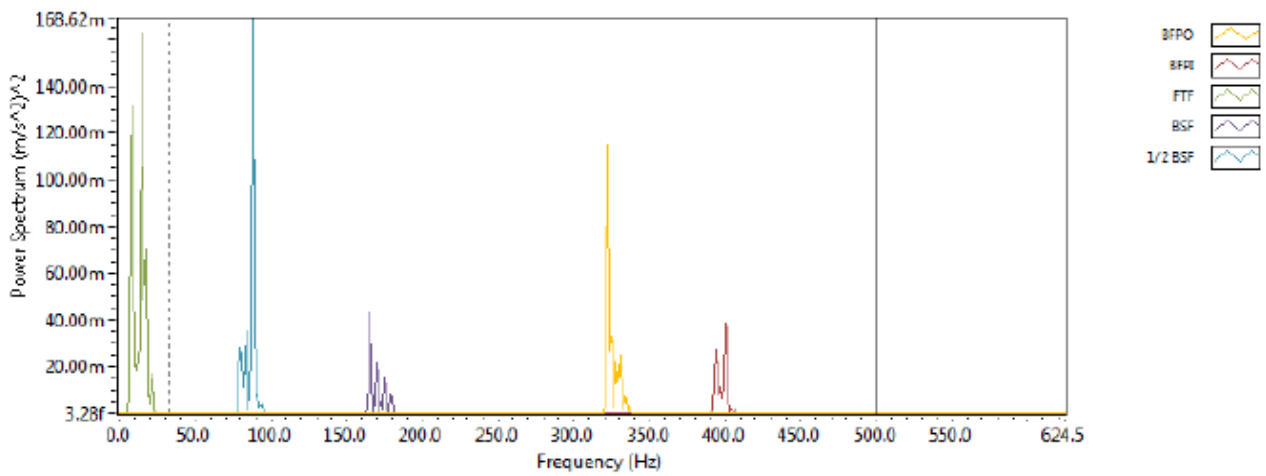

Fig. 7. Power spectrum determined with the envelope narrowband analysis method - point $B$ 

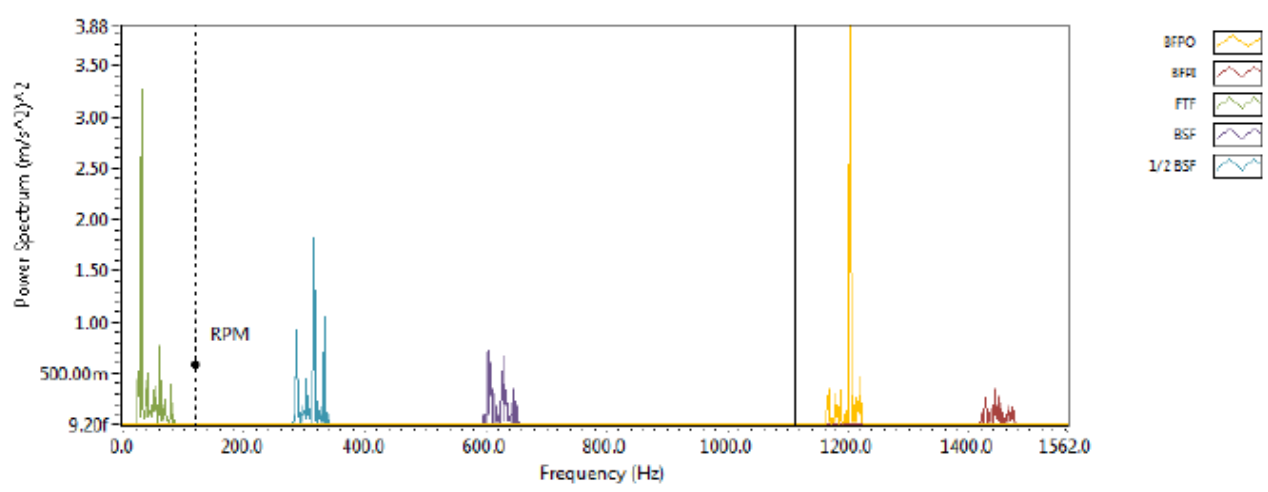

Fig. 8. Power spectrum determined with the envelope narrowband analysis method - point $A$
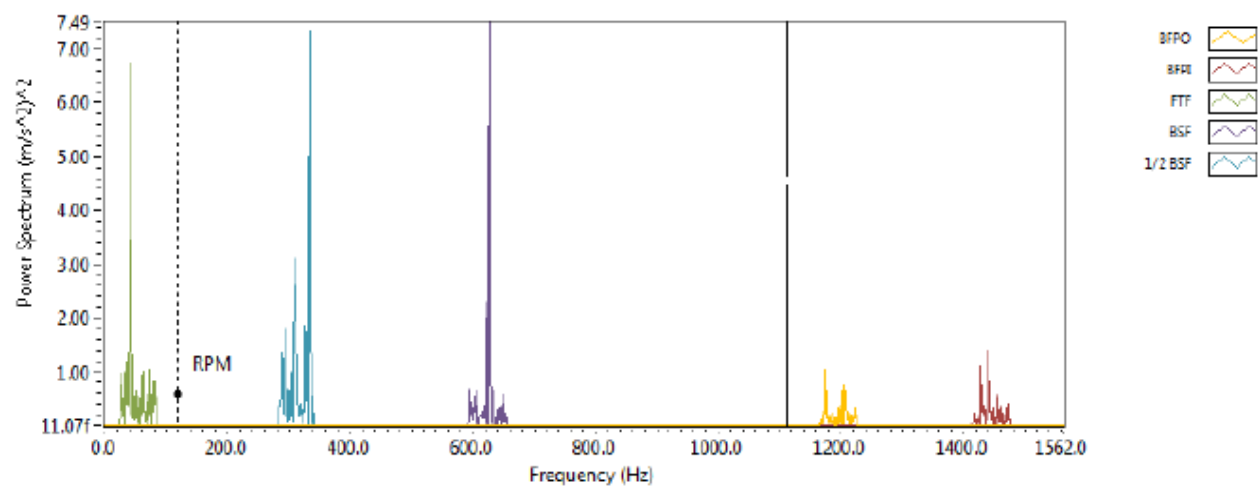

Fig. 9. Power spectrum determined with the envelope narrowband analysis method - point B

\section{CONCLUSIONS}

The tested bearing was a used bearing, which came from an engine with the expired service life resource, thus already having operational wears/damages of the particular elements of its structure. That is probably why, in the bearing envelope spectrum, already in its initial state, observed are all computation frequencies of the studied bearing. However, when comparing the levels of the determined average powers of the signal of the bearing, treated as operational (Fig. 10, 11 - red colour) in relation to the damaged one (Fig. 10, 11 - blue colour), there is a visible increase of the frequencies $f_{B P F O}, f_{B S F}$ and $0,5 \cdot f_{B S F}$ as directly associated with the damage of the internal race and the rolling element. There was also a significant increase of the power of frequency $f_{\mathrm{FTF}}$, which is theoretically associated with the defect of the rolling cage.

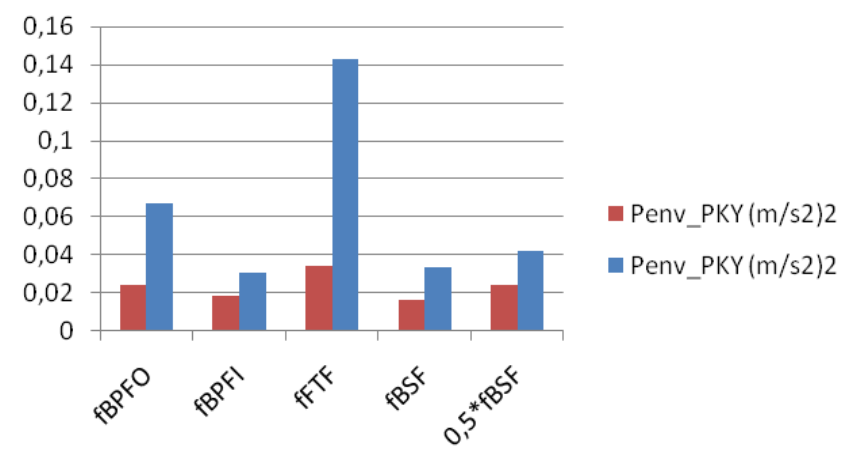

Fig. 10. Average characteristics frequency powers of bearing at point $A$

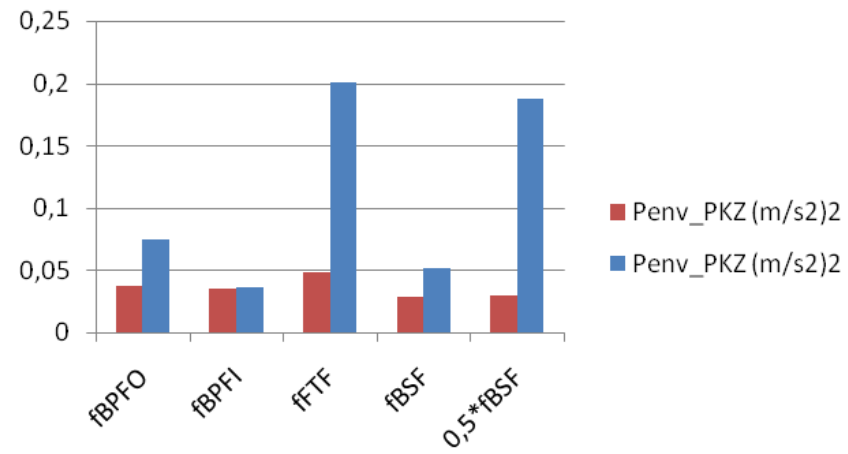

Fig. 11. Average characteristics frequency powers of bearing at point $B$

Generally, it was confirmed, that with jet engines, it was possible to analyse the bearing technical condition with the envelope vibroacoustic signal narrowband analysis. Whereas, when comparing the signal powers determined at cold start-up (rotor is rotated by a generator-starter and no fuel combustion processes occur - Tab. 3) and during a test of the engine (correct engine operation, at a small gas range, with present combustion processes - Tab. 4), there is visible even a one-hundred-fold difference in value. That in mind, during the trend analysis, we need to pay attention to the engine's operation range.

\section{REFERENCES}

1. Bloke M., Mitchel W., (1972), Vibration and acoustic measurement handbook, New York, Spartan Books, Chapter 22.

2. Cempel C. (1989), Vibroacoustics used, PWN, Warsaw, (in Polish). 
3. Dwojak J., Rzepiela M., (2003), Diagnostics and maintenance of rolling bearings, Guidance, Technical Diagnostics, Warsaw, (in Polish).

4. Muthukumarasamy A., Ganeriwala S., (2009), Diagnosis of Rolling Element Bearing Faults using Envelope analysis, SpectraQuest Tech Note.

5. Randall R., (2011), Vibration-based Condition Monitoring. Industrial, Aerospace and automotive applications, Willey and Sons, Ltd, Publication.

6. Żokowski M., Spychała J., Majewski P. (2015), The Use of the Vibroacoustic Method for Monitoring the Technical Condition of Aero Engines with Extended Time between Overhauls, Solid State Phenomena, 220, 283-288.

7. Żokowski M., Spychała J., Szczekala M., (2009), Diagnosis of the jet-propelled engine by vibration analysis, Transport Problems, 4(3), Part 2, 75-81.

8. Engine 88. Technical description and operating manual (1995) (in Polish).

9. Engine 89. Technical description (1988) (in Polish).

10. Engine D-30KU-154. Technical description and operating manual, (1992) (in Polish).

11. Helicopter Mi-24D. Technical description. Avionics. Poznan (1981) (in Polish).

12. Report of the Division for Aeroengines of Air Force Institute of Technology (2011), execution of the development project no. OR00010209, concluded between the Minister of Education and Higher Education and the Director of the Air Force Institute of Technology (in Polish). 